\title{
EFFECT OF RATE OF TEMPERATURE CHANGE ON THE TRANSFORMATIONS IN AN ALLOY STEEL
}

\author{
By Howard Scott
}

CONTENTS

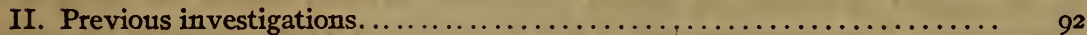

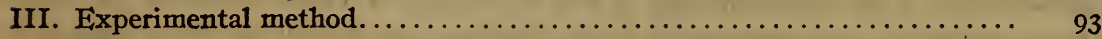

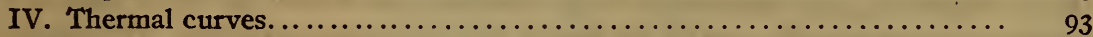

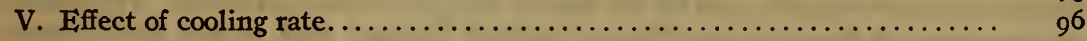

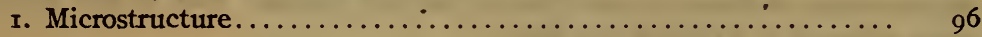

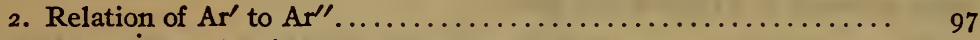

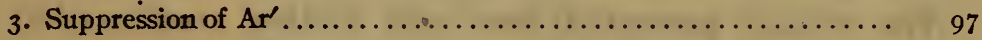

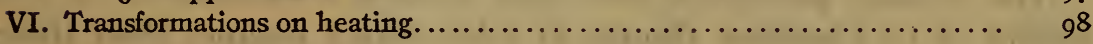

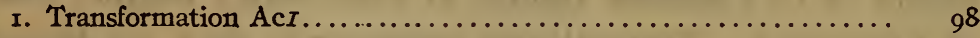

2. Effect of previous, cooling rate on $A c r-3 \ldots \ldots \ldots \ldots \ldots \ldots \ldots$

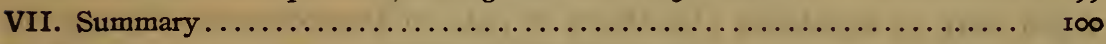

\section{INTRODUCTION}

Since Böhler discovered in r 903 , on cooling certain alloy steels, the phenomenon of a new and lower temperature transformation than the usual $\operatorname{Ar}_{3-2-I}$ obtained by increasing the maximum temperature ( $T$ max.) to which the material was heated, a considerable amount of work has been published, ${ }^{1}$ connecting this phenomenon with a large number of dissimilar steels of high alloy content. From the fact that the transformation divides itself, taking place at two widely separated temperatures, it has been called a split transformation. The significant facts established by recent investigators ${ }^{2}$ are $(a)$ that when the transformation occurs at the higher temperature, $\mathrm{Ar}^{\prime}$, troostite or a decomposition product is formed and $(b)$ that when the transformation occurs at the-lower temperature, $\mathrm{Ar}^{\prime \prime}$, the resulting structure is martensite. The terminology $\mathrm{Ar}^{\prime}$ and $\mathrm{Ar}^{\prime \prime}$, adopted here, is that of Portevin. ${ }^{3}$

1 Yatsevitch, Rev. de Met., 15, p. 65; rgr8, Bibliography to 1915.

${ }^{2}$ Dejean, Rev. de Met., 14, p. 641: 1917. Portevin, ibid., 14, p. 707; 1917. Edwards, J. Iron and Steel Inst., 93, p. 114; 1916.

Portevin, loc. cit. $106425^{\circ}-19$ 


\section{PREVIOUS INVESTIGATIONS}

Reviewing the work on this subject ${ }^{4}$ published in a recent issue of Revue de Metallurgie and referring in particular to his statement that martensite is a solution of carbide in alpha iron, H. Le Chatelier says:

How then can a theory already 20 years old demand new investigations? The reason for it is that we have not succeeded in proving directly the real presence of the transformation of iron during the very short duration of the quenching. The fall of temperature takes place at the rate of several hundred degrees per second and the observation of phenomena so rapid requires particularly sensitive methods of recording. I have attempted without success to observe the moment of the reappearance of the magnetic property during the quenching of bars $15 \mathrm{~mm}$ square, but the inequalities of temperature from one point to another in the mass conceal the phenomenon. M. Chevenard ${ }^{5}$, in working on wires of a diameter 100 times smaller and using as a characteristic of the transformation of iron the change of length instead of the variation of magnetism, has surmounted for the first time the difficulties which seemed at first view insurmountable, and he has done it with an extreme precision. The thermal measurements of. Portevin and Garvin ${ }^{6}$ and of Dejean ${ }^{7}$ lead to the same conclusions, although in a fashion less direct.

The results presented here add further confirmation of the theory of Le Chatelier, though in a less direct manner than those of Chevenard. Thermal and microscopic data are brought forward here to establish the effect of rate of temperature change on the temperature and nature of the transformations in a steel of the composition $\mathrm{C}, \mathrm{I} .75 ; \mathrm{Mn}, 0.26$; $\mathrm{Co}, 2.90 ; \mathrm{Cr}, \mathrm{I} 5.0$.

Similar work has been done by Edwards ${ }^{8}$ on a steel of the composition $\mathrm{C}, 0.63 ; \mathrm{Cr}, 6.15 ; \mathrm{Si}, 0.07 ; \mathrm{Mn}, 0.17$.

However, he arrives at the conclusion that-

The maximum hardness was obtained when the thermal transformation had been entirely prevented, and when this was accomplished the steel was purely martensitic in structure.

The present work fails to confirm this statement, as does that of the investigators already referred to. Edwards was unable to observe the transformation $\mathrm{Ar}^{\prime \prime}$ with the formation of martensite, probably for the reasons given by Rosenhain ${ }^{\circ}$ in his discussion of Edwards' paper.

Yatsevitch, ${ }^{10}$ Dejean ${ }^{11}$, and Honda ${ }^{12}$ have used two or three cooling rates in their experiments with varying $T$ max., and their results show, as do Edwards's that the transformation split occurs for lower values of $T$ max. with faster cooling rates.

I.e Chatelier, Rev. de Met., 14, p. 601; r917.

- Chevenard, Rev. de Met., 14, p. 6ro; r9r7.

- Portevin and Garvin, Rev. de Met., 14, p. 607; 1917.

' Dejean, Rev. de Met., 14, p. 64x; r9x7.

8 Edwards, loc. cit.
- Rosenhain, J. Iron and Steel Inst., 93, p. 147; 1916.

10 Yatsevitch, loc. cit.

11 Dejean. loc. cit.

12 Honda and Murakami, Sci. Rep. Tohoku Imp. Univ., 6, p. 235; 1918. 


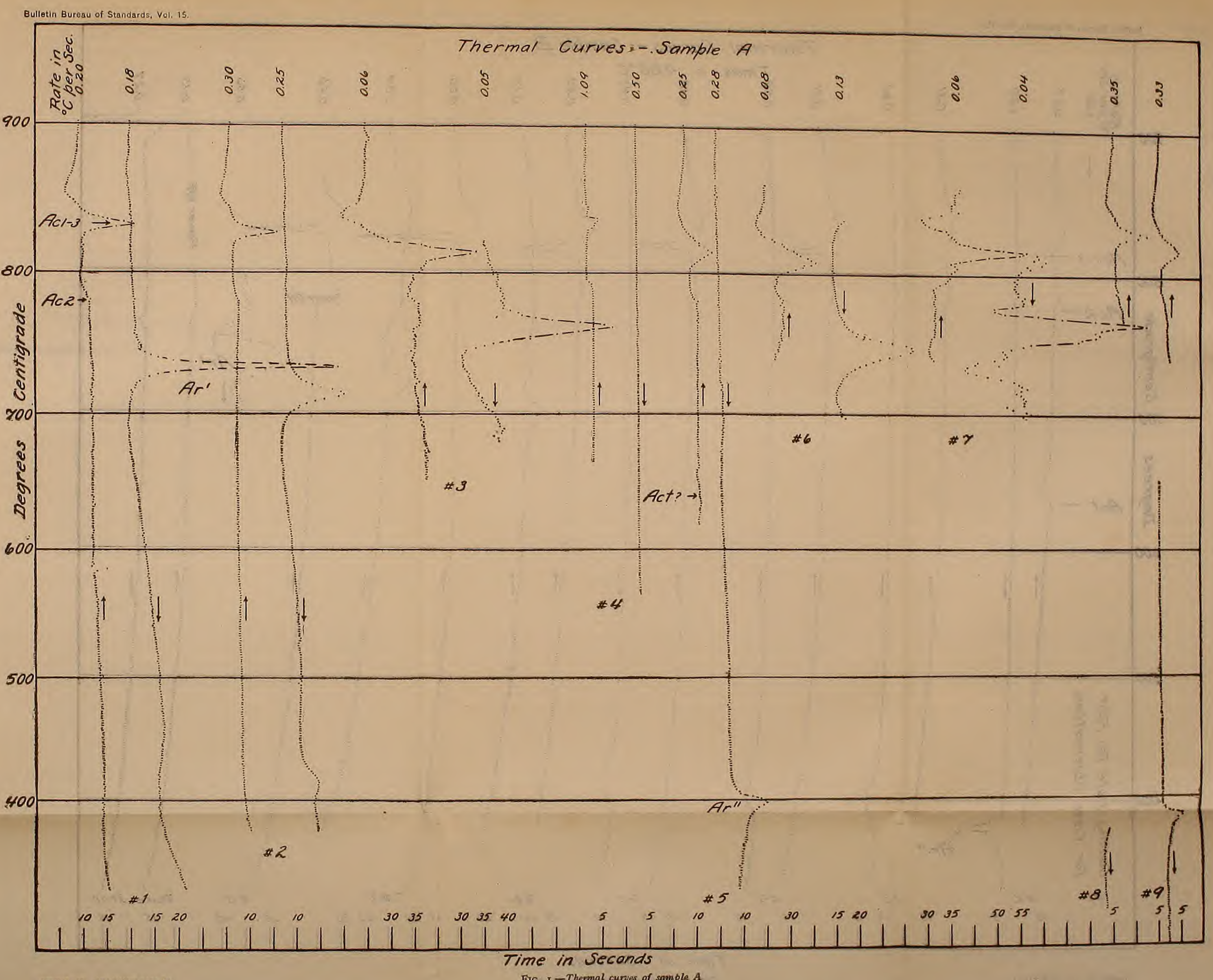


The previous investigators in this field have laid particular stress on the variation of $T$ max., the rate remaining constant, while the variation of rate, $T$ max. remaining constant, has received little attention. The present work attempts to apply the latter method to the investigation of an alloy steel with the object in view of correlating the results of that method with those of the former and to establish the relationship between the several phenomena observed.

\section{EXPERIMENTAL METHOD}

The method employed for obtaining the thermal curves was to heat the samples, attached to the hot junction of a $0.5 \mathrm{~mm}$ diameter platinum, 90 platinum-ro rhodium thermocouple, in an electric vacuum furnace, taking potential measurements on a dial potentiometer and measuring the time interval on a chronograph, as described in the Bureau of Standards Scientific Paper 213. The furnace, however, was one recently built at the Bureau, a modified form of the one described by Rosenhain ${ }^{13}$ and in use at the National Physical Laboratory. This furnace, which will be described at a later date, was admirable for the purpose at hand, as extreme rates of temperature change can be obtained with smooth curves over long ranges.

\section{THERMAL CURVES}

The curves of Figs. I and 2 were plotted by the inverse rate method from readings taken every 0.02 millivolt (approximately $2^{\circ} \mathrm{C}$ ) except for several extremely fast runs, which, however, are plotted on that basis.

The curves of Fig. I are a preliminary series taken on sample A of about $10 \mathrm{~g}$ mass to locate the transformation ranges and without fully knowing the characteristics of the material. The data for the curves of Fig. 2 were taken on sample B, mass $0.8 \mathrm{I} \mathrm{g}$, keeping $T$ max. constant and extending the observations to lower temperatures than for sample $A$. The values given for rate of temperature change were reduced from the inverse rate curve observations taken on heating just before $A c r-3$ and on cooling midway between $\mathrm{Ar}^{\prime}$ and $\mathrm{Ar}^{\prime \prime}$.

The transformations as designated on the curves of Figs. I and 2 are Act, an evolution of heat on heating a sample previously cooled at a rate that gave $\mathrm{Ar}^{\prime \prime}$; Ac2, the magnetic transformation; $\mathrm{Ac}_{1}-3$, the transformations $\mathrm{Ac}_{1}$ and $\mathrm{Ac}_{3}$ merged or nearly superimposed; $\mathrm{Ar}^{\prime}$, the upper transformation of the split Ar transformations; and $\mathrm{Ar}^{\prime \prime}$, the lower transformation. The temperature values of these transformations are collected in Table $\mathrm{I}$. 


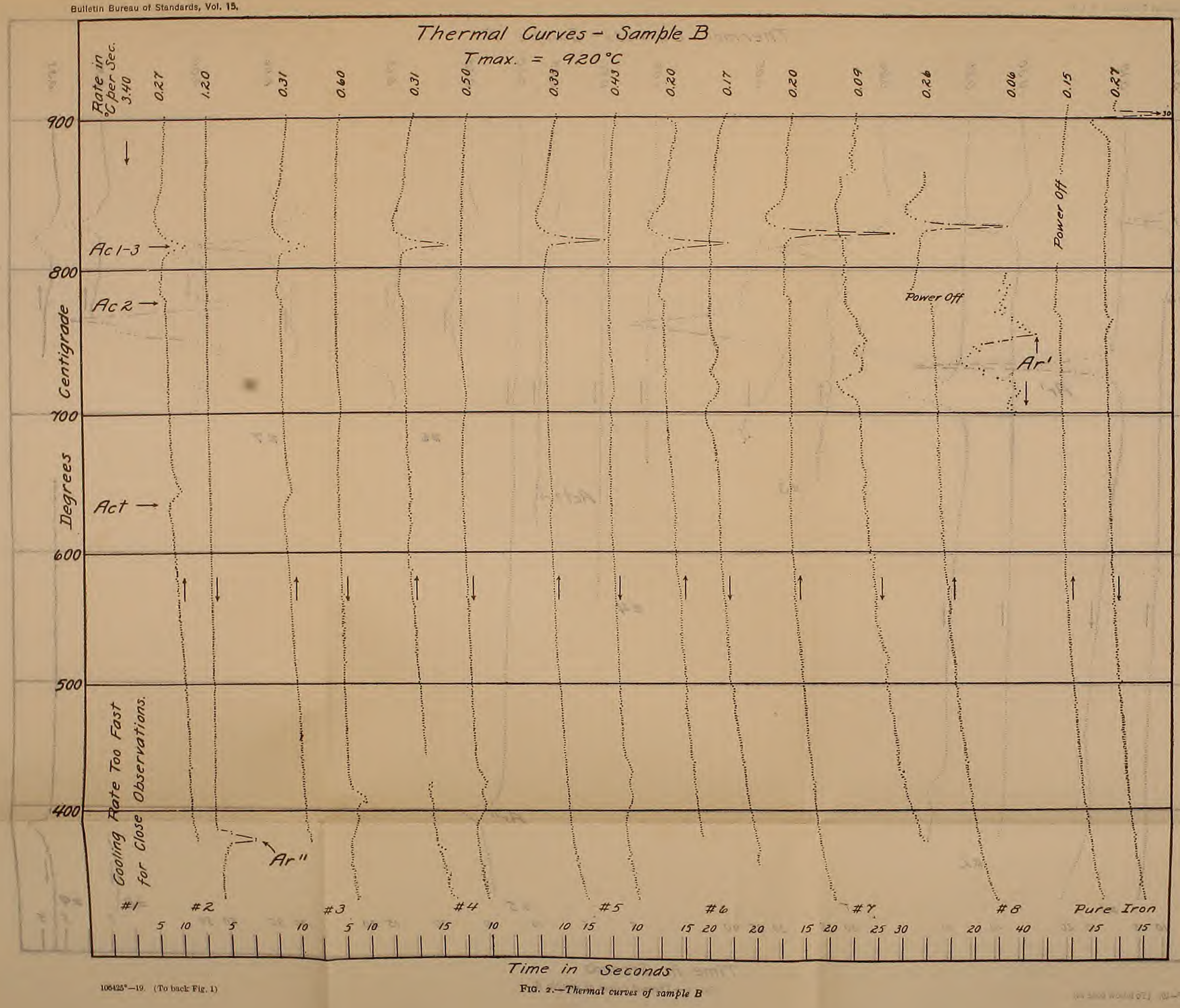




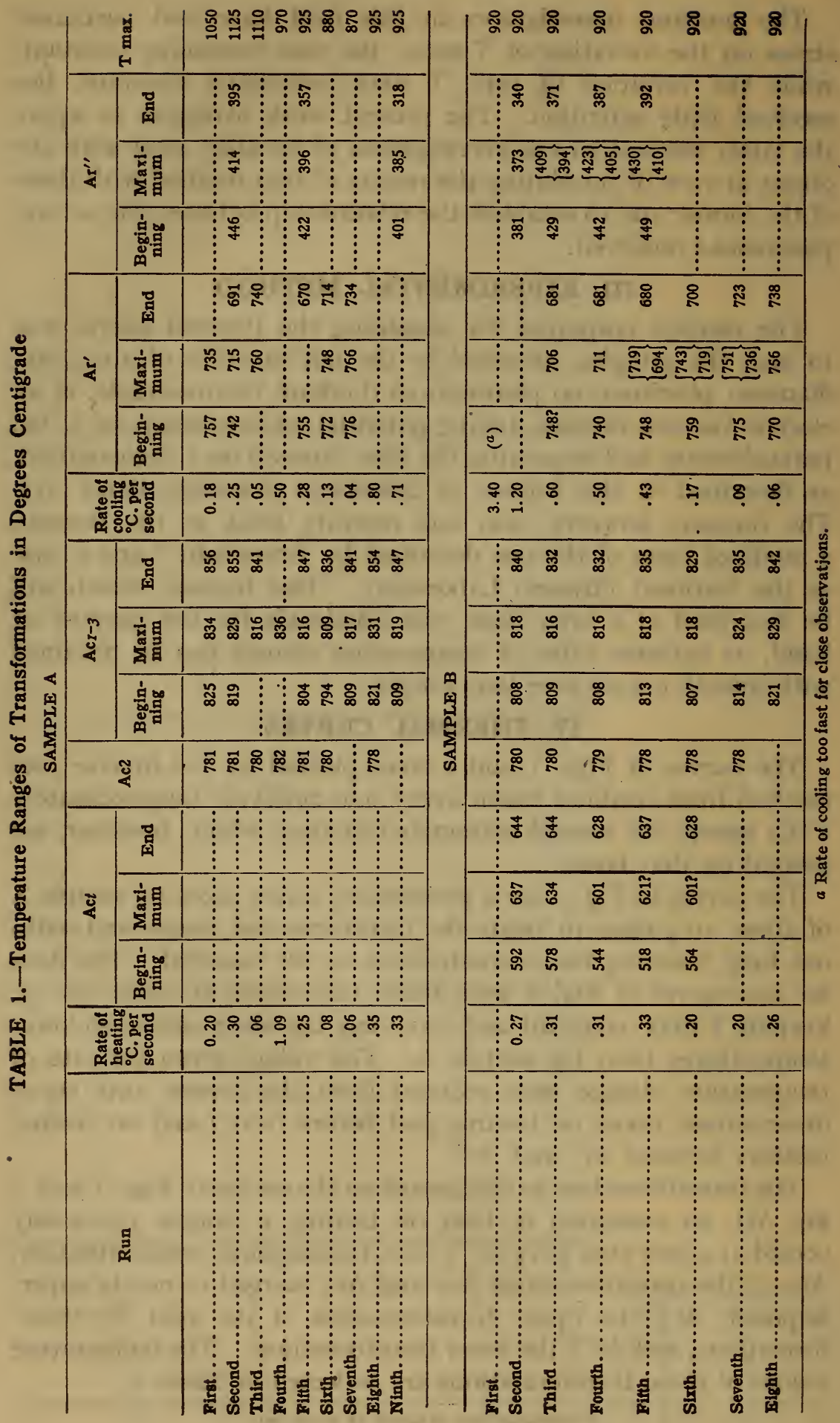


The appropriateness of the transformation notation AcI-3 and Act will be seen from the discussion of those transformations.

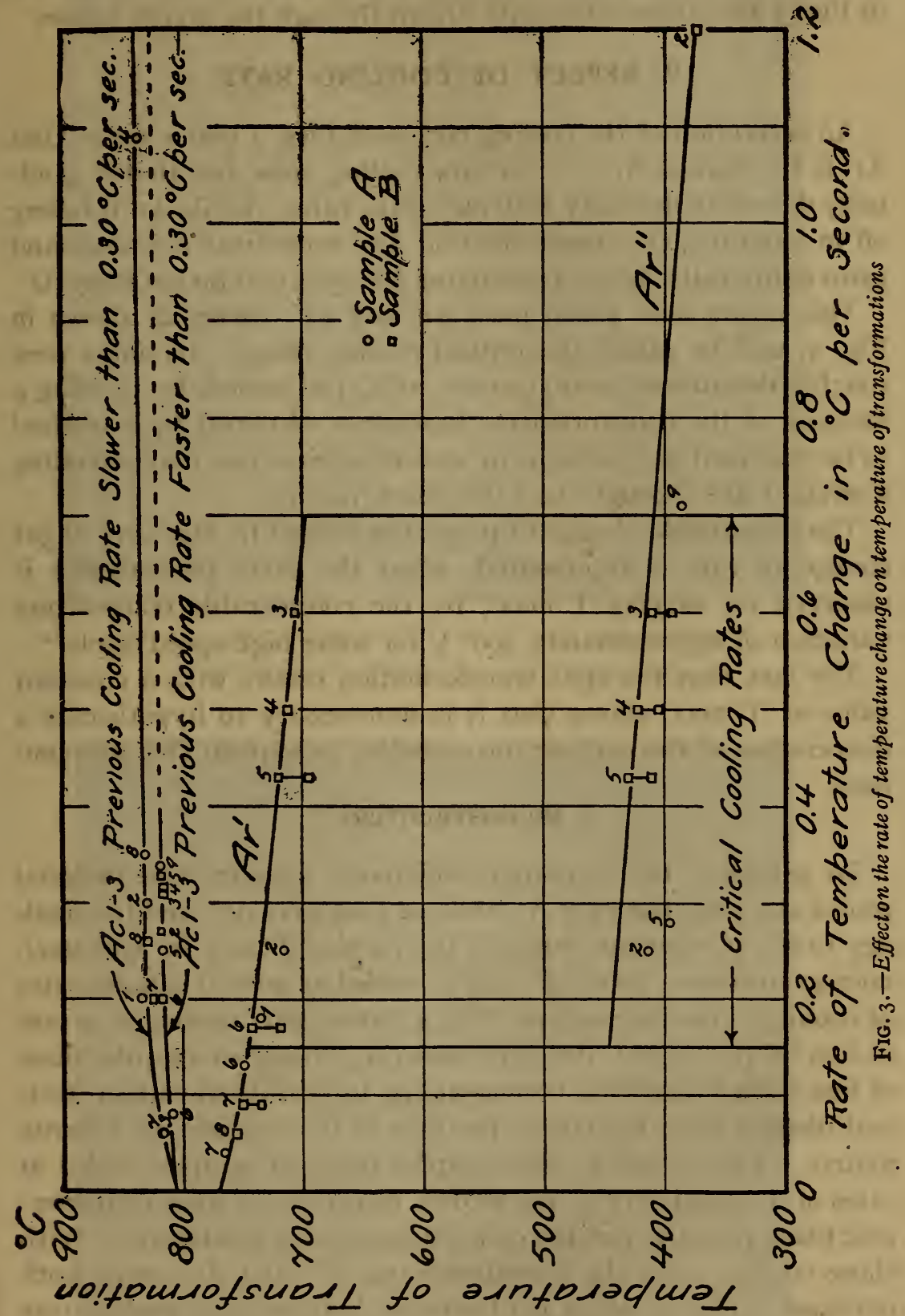

Two values for the maximum transformation temperature indicate a double peak. In Fig. 3 the temperature values of $\mathrm{Ac}_{I-3}, \mathrm{Ar}^{\prime}$, and $\mathrm{Ar}^{\prime \prime}$ given in Table $\mathrm{I}$ are plotted against rate of temperature 
change in degrees centigrade per second. No attempt is made to interpret the double peaks, and the lines representing $\mathrm{Ar}^{\prime}$ and $\mathrm{Ar}^{\prime \prime}$ in Fig. 3 are rather arbitrarily drawn through the higher values.

\section{EFFECT OF COOLING RATE}

An inspection of the cooling curves of Figs. I and 2 shows that $\mathrm{Ar}^{\prime}$ is the normal $\mathrm{Ar}_{3-2-I}$ of slow cooling rates, but that it gradually dies off in intensity with increasing rate. While $A r^{\prime}$ is falling off in intensity, the transformation $\mathrm{Ar}^{\prime \prime}$ comes into existence and gains in intensity, being a maximum for rates that do not show $\mathrm{Ar}^{\prime}$.

This region over which both $\mathrm{Ar}^{\prime}$ and $\mathrm{Ar}^{\prime \prime}$ occur, as shown in Fig. 3, will be called the critical cooling range. Its limits were roughly determined as 0.15 and $0.70^{\circ} \mathrm{C}$ per second, by plotting a measure of the transformation intensities, obtained by a method to be described in a subsequent section, against rate and extending a straight line through the values back to zero.

The remarkable change in properties caused by this very slight change in rate is represented, when the same phenomenon is observed on varying $\mathrm{T}$ max., by the considerable temperature variation of approximately $300^{\circ} \mathrm{C}$ for some high-speed steels. ${ }^{14}$

The fact that the split transformation occurs with a constant value of $T$ max. shows that it is unnecessary to hypothecate a dissociation of the carbide (or carbides) to explain this phenomenon.

\section{MICROSTRUCTURE ${ }^{15}$}

To establish the structural difference between the material cooled at a rate that gave $\mathrm{Ar}^{\prime}$ and one that gave $\mathrm{Ar}^{\prime \prime}$ and the analogy to the phenomena obtained by varying $T$ max. for this steel, micrographs were taken of samples cooled at several definite rates of cooling. The micrograph, Fig. 4, taken after cooling at a rate of $0.0 r^{\circ} \mathrm{C}$ per second, $\mathrm{Ar}^{\prime}$ only occurring, shows an irregular mass of fine carbide particles, corresponding to pearlite in carbon steels and distinct from the coarse particles of free carbide, in a ferrite matrix. Figs. 5 and 6, micrographs, taken of samples cooled at rates of 0.30 and $0.33^{\circ} \mathrm{C}$ per second, respectively, show characteristic black troostite patches on a background of martensite. With those cooling rates the transformations $\mathrm{Ar}^{\prime}$ and $\mathrm{Ar}^{\prime \prime}$ were both obtained. Fig. 7, which is of sample A following a cooling rate of $0.7 \mathrm{I}^{\circ} \mathrm{C}$ per second, shows a martensitic structure although the

14 Honda and Murakami, loc. cit.; Carpenter, loc. cit.

15 Micrographs by H. S. Rawdon. 


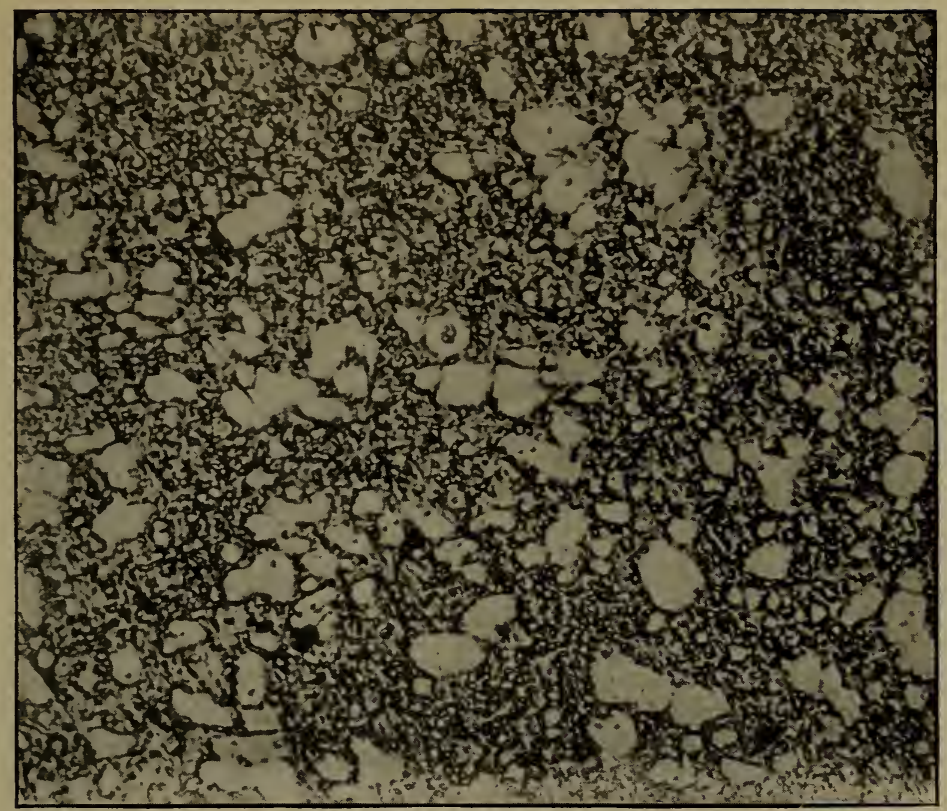

FIG. 4.-Cooling rate, $O . O I^{\circ} \mathrm{C}$ per second. Transformation $A r^{\prime}$ Magnification rooox. Etched in 2 per cent $\mathrm{HNO}_{3}$ in alcohol

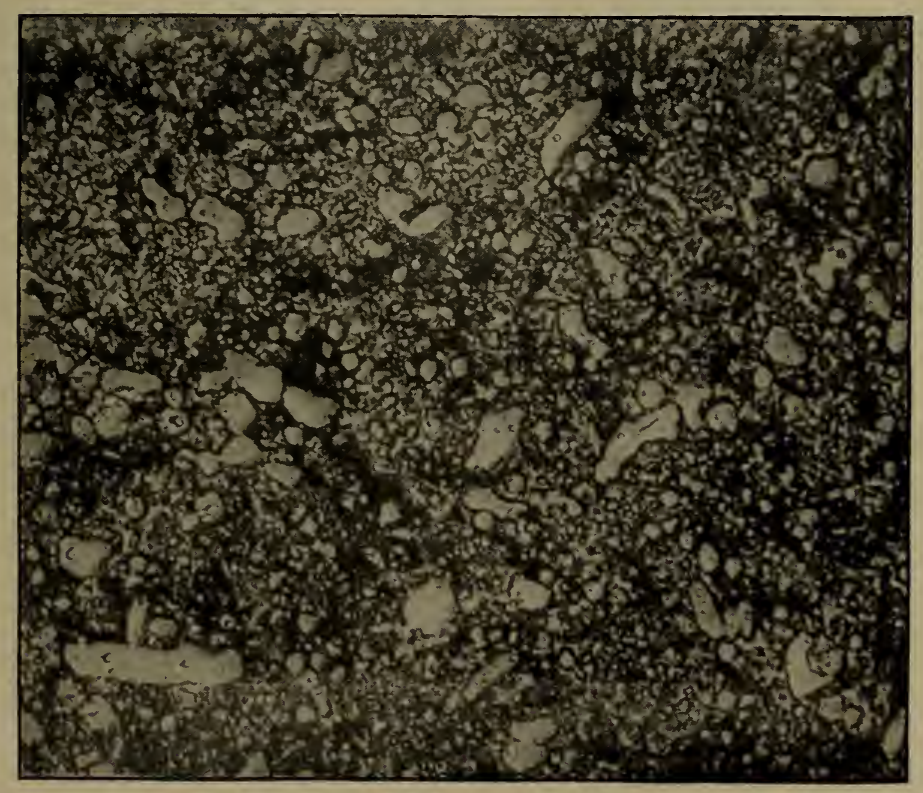

FIG. 5.-Conling rate, $0.30^{\circ} \mathrm{C}$ per second. Transformation Ar' and A $r^{\prime \prime}$ Magnification rooox. Etched in 2 per cent $\mathrm{HNO}_{3}$ in alcohol 
Bulletin Bureau of Standards, Vol. 15

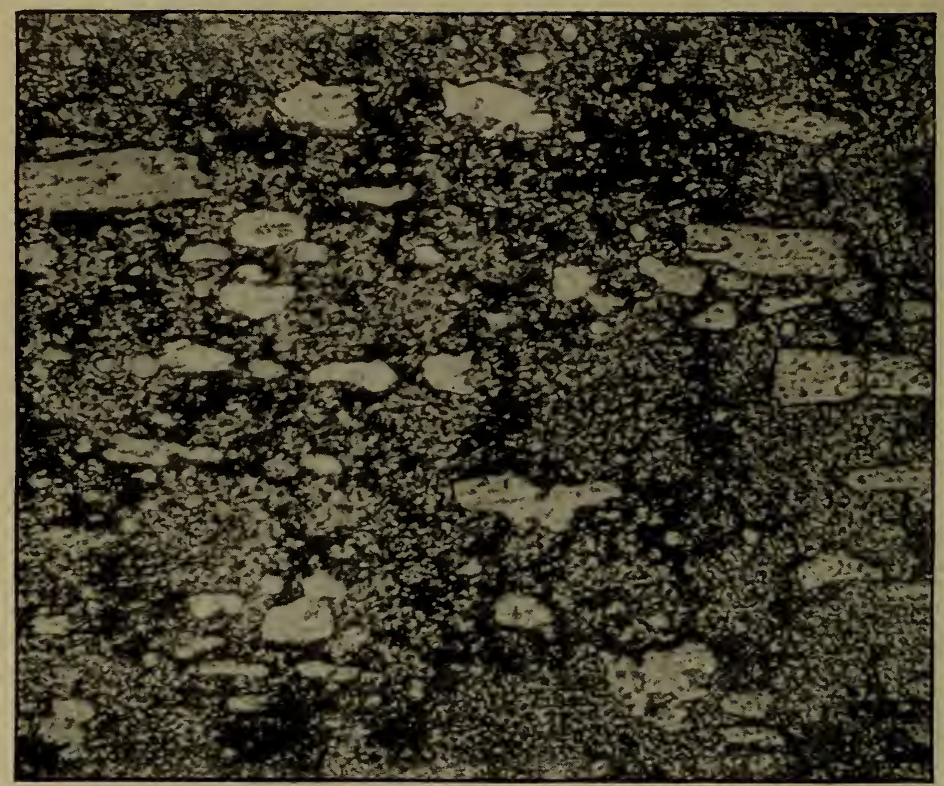

Fig. 6.-Cooling rate, $0.33^{\circ} \mathrm{C}$ per second. Transformation $A r^{\prime}$ and $A r^{\prime \prime}$ Magnification rooox. Etched in 2 per cent $\mathrm{HNO}_{3}$ in alcohol

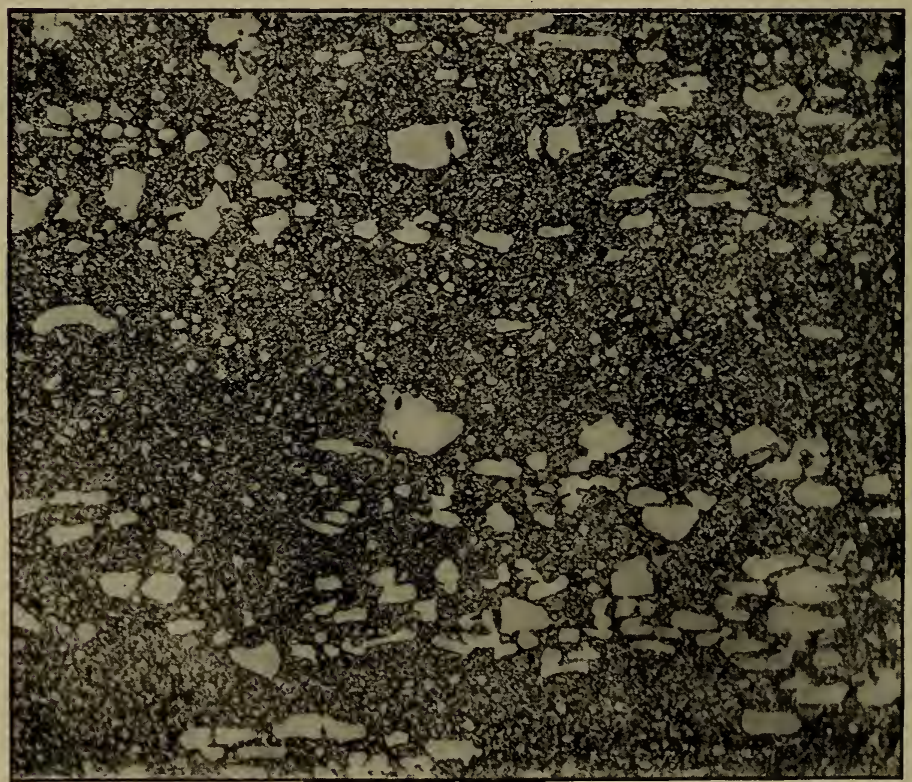

FIG. 7.-Cooling rate, $0.7 I^{\circ} \mathrm{C}$ per second. Transformation Ar" Magnification rooox. Etched in 2 per cent $\mathrm{HNO}_{3}$ in alcohol 
needlelike markings, characteristic of high-carbon steels, are only slightly evident.

The conclusions to be drawn from the preceding microscopic evidence are that troostite or a decomposition product forms with the transformation $\mathrm{Ar}^{\prime}$ and martensite with the transformation $A r^{\prime \prime}$, precisely what obtains when the same transformations are observed in other alloy steels with varying $T$ max.

\section{RELATION OF "Ar" TO "Ar" "}

The radical structural difference between the material showing $\mathrm{Ar}^{\prime}$ and that showing $\mathrm{Ar}^{\prime \prime}$ presumes a similar radical difference in the transformations $\mathrm{Ar}^{\prime}$ and $\mathrm{Ar}^{\prime \prime}$. To demonstrate the possibility of this difference, the intensities of the transformations $\mathrm{AcI}-3, \mathrm{Ac} 2, \mathrm{Ar}^{\prime}$, and $\mathrm{Ar}^{\prime \prime}$ have been estimated by means of a planimeter measuring the area of the positive departure of the thermal curves from the assumed neutral body curves through the respective transformation ranges. The results given in Table 2 show a well-marked loss in intensity of the sum of the areas of $\mathrm{Ar}^{\prime}$ and $\mathrm{Ar}^{\prime \prime}$ at the cooling rate $1.20^{\circ} \mathrm{C}$ per second, which gives $\mathrm{Ar}^{\prime \prime}$ above. On the assumption that $\mathrm{Ar}^{\prime \prime}$ is no new transformation other than $\operatorname{Ar}_{3}, 2$, or $I$, the conclusion is that some one or more of the transformations $\operatorname{Ar}_{3}, 2$, and $I$ constituting $\mathrm{Ar}^{\prime}$ is suppressed.

TABLE 2.-Areas of Thermal Curves in Square Millimeters Corresponding to Hea Effects of Transformations in Sample B

\begin{tabular}{|c|c|c|c|c|c|c|c|}
\hline Run & Ac1-S & Ac2 & $\underset{\substack{\text { Ac1-S+ } \\
\text { transtor- } \\
\text { mation } \\
\text { Aca }}}{ }$ & $\begin{array}{l}\text { Cooling } \\
\text { rate, de- } \\
\text { grees per } \\
\text { second }\end{array}$ & $\mathbf{A r} \mathbf{r}^{\prime}$ & $\mathbf{A r \prime \prime}$ & $\begin{array}{l}\text { Ar'trans- } \\
\text { forma- } \\
\text { tion + Ar" }\end{array}$ \\
\hline First... & & & & 3.40 & & & \\
\hline Second................. & 36 & 74 & 110 & 1.20 & ... & 84 & 84 \\
\hline Third................ & 40 & 66 & 106 & .60 & 26 & 72 & 98 \\
\hline Fourth.... & 40 & 68 & 108 & .50 & 38 & 60 & 98 \\
\hline Fitth................. & 64 & 64 & 128 & .43 & 56 & 48 & 104 \\
\hline Sixth.................... & 60 & 64 & 124 & .17 & 100 & & 100 \\
\hline Seventh............. & 72 & 72 & 144 & .09 & 120 & & 120 \\
\hline Eighth.............. & 72 & & 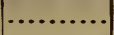 & .06 & 116 & & 116 \\
\hline Average...... & & 68 & 120 & & & & \\
\hline
\end{tabular}

\section{SUPPRESSION OF "ArI"}

The preceding. conclusion agrees with the generally accepted conception that martensite is a solid solution of cementite in some form of iron. This means that $\operatorname{Ar}_{I}$ is suppressed with the formation of martensite and further evidence is not wanting. The transformation intensities indicate that a heat effect of the mag- 
nitude of $\operatorname{Ar} I$ is missing at $\mathrm{Ar}^{\prime \prime}$. The work of Honda on the magnetic properties of tungsten steels in a paper before the September meeting of the Journal of the Iron and Steel Institute, however, shows that the carbide is retained in solution at $\mathrm{Ar}^{\prime \prime}$ for the carbide in solution does not undergo the transformation $A o$. The transformations Act and AcI-3 offer still further substantiation to which attention will be called in their discussion.

There still remains the possibility that one of the other transformations, $\mathrm{Ar}_{3}$ or 2 , is suppressed. This, however, is manifestly impossible, for $\mathrm{A}_{3}$ and $\mathrm{A}_{2}$ coincide when $\mathrm{A}_{3}$ is depressed below the normal temperature of $\mathrm{A}_{2}{ }^{10}$ and martensite is magnetic. The magnetic curves of Honda and Murakami ${ }^{17}$, taken on a number of tungsten steels showing a split transformation with increasing $\mathrm{T}$ max., also indicate the occurrence of $\mathrm{A} 2$ at $\mathrm{Ar}^{\prime \prime}$.

The conclusion that must therefore be adopted is that $\operatorname{Ar} I$ is suppressed with the formation of martensite, or that $\mathrm{Ar}^{\prime \prime}$ constitutes the transformations $\operatorname{Ar}_{3}$ and 2.

\section{TRANSFORMATIONS ON HEATING}

The thermal curves of Figs. I and 2 show two transformations Ac $I-3$ and Ac2 occurring uniformly within narrow temperature limits and a transformation Act occurring only following certain cooling rates. The identity of Ac2 is established by its markedly characteristic shape and its uniform occurrence at about $780^{\circ} \mathrm{C}$ which is in close proximity to its maximum, $768^{\circ}$, in pure iron. This phenomenon of AcI occurring above Ac2 in alloy steels is not new and has been well established by Moore ${ }^{18}$ for a chromium steel. The transformation AcI-3 hardly needs identification, although attention should be called to its sluggish ending which indicates that the transformations concerned do not completely coincide. This is further illustrated by the change in area of the peak, which is evidently AcI from the effect of previous cooling rate on its position, with the temperature of its occurrence.

\section{TRANSFORMATION "Act"}

The transformation Act is indicated by an inflection to the left which denotes an evolution of heat on the heating curve and occurs over a considerable temperature range. It is a maximum following cooling rates that give $\mathrm{Ar}^{\prime \prime}$ alone, and loses in intensity following decreasing rates through the critical cooling range, becom-

${ }^{16}$ Honda and Takagi, Sci. Rep. Tohoku Imp. Univ., 6, p. 324; 1918.

17 Honda and Murakami, loc. cit.

${ }_{18}$ Moore, J. Iron and Steel Inst., 81, p. 268; 19 ro. 
ing zero when $\mathrm{Ar}^{\prime}$ alone occurs. It is therefore roughly proportional in intensity to $\mathrm{Ar}^{\prime \prime}$ or the amount of martensite present. By its analogy to tempering the conclusion may be drawn that Act represents the precipitation of the carbide in solution to form at first troostite and as it progresses the coarsening of the carbide.

This phenomenon of a heat evolution on heating steels that show $\mathrm{Ar}^{\prime \prime}$ was observed by Carpenter ${ }^{19}$ on differential thermal curves with which $\mathrm{T}$ max. was varied and connected with tempering.

The nature of Act, a gradual building up of the heat evolution over a long temperature range, may throw some light on the spontaneous heat evolution and also the change in other physical properties of quenched steels as observed by Hadfield and Brush ${ }^{20}$, by Matsushita ${ }^{21}$, and by Campbell ${ }^{22}$. The indications are that the transformation starts to a minute degree at very low temperatures, possibly at ordinary temperatures, particularly in carbonsteels which temper at lower temperatures than alloy steels.

The existence of Act as an evolution of heat following cooling rates that give $A r^{\prime \prime}$ is further confirmation of the suppression of ArI with the formation of martensite.

\section{EFFECT OF PREVIOUS COOLING RATE ON "AC1-3"}

It will be seen on examining Fig. 3 that practically all the temperature values for the maximum of AcI-3 lie on two smooth curves. The data of Table I show that the runs which correspond to the numbers on the upper curve were obtained following cooling rates that gave $\mathrm{Ar}^{\prime}$ predominant and those on the lower curve following cooling rates that gave $\mathrm{Ar}^{\prime \prime}$ predominant. The temperature interval, $10^{\circ}$ to $15^{\circ} \mathrm{C}$, between those two curves may therefore be attributed to the state of division of the carbide resulting from the previous heat treatment.

The phenomenon noted in the preceding paragraph offers still further substantiation of the suppression of $\mathrm{Ar}^{\prime}$ with the formation of martensite.

It may be of interest to note that the curves of Fig. 3 drawn through the temperature values of $\mathrm{AcI}_{-} 3$ and $\mathrm{Ar}^{\prime}$ do not point toward a common equilibrium temperature Aer.

\footnotetext{
19 Carpenter, J. Iron and Steel Inst., 67, p. 433; 1905.

${ }^{20}$ Hadfield and Brush, Proc. Royal Soc., 93, p. r88; 1917.

21 Matsushita, Sci. Rep. Tohoku Imp. Univ., 7, p. 43; r918.

22 Campbell, Reprint J. Iron and Steel Inst., 98,p. 42r; I9I8.
} 


\section{SUMMARY}

The results of previous investigators have been taken to show that with the occurrence of a split transformation on cooling alloy steels from increasingly higher temperatures $(a)$ that when the higher temperature transformation $\mathrm{Ar}^{\prime}$ is observed with low values of $T$ max., troostite or a decomposition product results and $(b)$ that when the lower temperature transformation $A r^{\prime \prime}$ is observed with high values of $T$ max., martensite is the resulting product.

The present investigation has shown for a certain alloy steel that on varying the rate of cooling, the maximum temperature remaining constant, a strictly analogous phenomenon is observed, increasing rate of cooling having the same effect as increasing $T$ max.

Conclusions are drawn to the effect that-

(a) The transformation $\mathrm{Ar}^{\prime}$ consists of the transformations $\operatorname{Ar}_{3}, 2$, and $I$.

(b) The transformation $\mathrm{Ar}^{\prime \prime}$ consists of the transformations $\mathrm{Ar}_{3}$ and 2.

(c) The transformation $\operatorname{Ar} I$, suppressed when $A r^{\prime \prime}$ is observed, occurs on heating as Act with an evolution of heat and the formation of troostite or a coarser condition of the carbide.

(d) The maximum of the transformation AcI-3 occurs at a higher temperature when the previous cooling rate gave $\mathrm{Ar}^{\prime}$ than when it gave $\mathrm{Ar}^{\prime \prime}$.

The author desires to express his indebtedness to H. S. Rawdon for the micrographic work and to Miss P. L. Thompson for her skillful assistance in preparing the experimental data.

WASHINGTON, December 23, 1918. 